\title{
Novel Approaches for Immunosuppression in Graves' Hyperthyroidism and Associated Orbitopathy
}

\author{
Alan Chun Hong Lee $e^{a, b}$ George J. Kahaly ${ }^{b}$ \\ a Division of Endocrinology and Metabolism, Department of Medicine, Queen Mary Hospital, Hong Kong, China; \\ ${ }^{b}$ Department of Medicine I, Johannes Gutenberg University Medical Center, Mainz, Germany
}

\section{Keywords}

Novel approaches · Immunosuppression · Graves'

hyperthyroidism · Graves' orbitopathy

\begin{abstract}
Background: Both Graves' hyperthyroidism (GH) and Graves' orbitopathy (GO) are associated with significant adverse health consequences. All conventional treatment options have limitations regarding efficacy and safety. Most importantly, they do not specifically address the underlying immunological mechanisms. We aim to review the latest development of treatment approaches in these two closely related disorders. Summary: Immunotherapies of GH have recently demonstrated clinical efficacy in preliminary studies. They include ATX-GD-59, an antigen-specific immunotherapy which restores immune tolerance to the thyrotropin receptor; iscalimab, an anti-CD40 monoclonal antibody which blocks the CD40-CD154 costimulatory pathway in B-T cell interaction; and $\mathrm{K} 1-70$, a thyrotropin receptor-blocking monoclonal antibody. Novel treatment strategies have also become available in GO. Mycophenolate significantly increased the overall response rate combined with standard glucocorticoid (GC) treatment compared to GC monotherapy. Tocilizumab, an anti-interleukin 6 receptor monoclonal antibody, displayed strong anti-inflammatory action in GCresistant cases. Teprotumumab, an anti-insulin-like growth
\end{abstract}

factor 1 receptor monoclonal antibody, resulted in remarkable improvement in terms of disease activity, proptosis, and diplopia. Further, rituximab appears to be useful in active disease of recent onset without impending dysthyroid optic neuropathy. Key Messages: Therapeutic advances will continue to optimize our management of $\mathrm{GH}$ and associated orbitopathy in an effective and safe manner.

C 2020 European Thyroid Association Published by S. Karger AG, Basel

\section{Introduction}

Graves' disease (GD) accounts for 75\% of hyperthyroidism in iodine-replete geographical areas. Approximately one-fifth of GD patients develop Graves' orbitopathy (GO), which is the most common extrathyroidal manifestation of GD [1,2]. Recent population-based studies have demonstrated that hyperthyroidism is associated with increased risks of all-cause mortality and cardiovascular diseases $[3,4]$. GO results in significant disfigurement and disability and adversely impacts on quality of life, psychological well-being, and socioeconomic burden [5-7].

Thioamide antithyroid drugs (ATDs) and radioactive iodine (RAI) were introduced in the 1940s. Together with total thyroidectomy, these are the three established treatment modalities of Graves' hyperthyroidism (GH). Sys- 
temic glucocorticoids (GCs) were commonly employed in active GO since the 1950s. Over the past decade, we have witnessed the emergence of novel therapeutics which better target the immunological mechanisms underpinning GH and GO. This review aims to discuss the latest development of treatment approaches in these two closely related disorders.

\section{GH: Limitations of Current Therapy}

Approximately $60 \%$ of clinicians chose ATDs as the first-line treatment of $\mathrm{GH}$ in a recent survey [8], consistent with the latest recommendation by the European Thyroid Association [1]. However, ATDs carry a low to very low but non-negligible risk of severe or even potentially life-threatening toxicities, including agranulocytosis, hepatotoxicity, pancreatitis, and ANCA-positive vasculitis [9]. The high relapse rate of $50 \%$ after treatment withdrawal [8] implies that GH patients require resumption of ATDs or definitive treatment. Successful thyroid ablation by RAI or total thyroidectomy necessitates lifelong thyroid hormone replacement, but about $5-10 \%$ of levothyroxine-treated patients experienced persistent symptoms despite normal serum TSH levels [10]. RAI is associated with progression or de novo development of GO, especially in at-risk patients [2]. Although total thyroidectomy offers rapid and definitive cure of hyperthyroidism, surgical or anesthetic complications may occur. None of the current treatment options of GH target the key immunopathogenic mechanisms. Although the levels of thyrotropin receptor autoantibody (TSH-R-Ab), which is the specific biomarker of GD $[11,12]$, decline during ATD therapy, ATDs primarily inhibit thyroid hormone biosynthesis only, and whether they directly target thyroid autoimmunity remains inconclusive. In recent years, several therapeutic agents have been developed to treat GH through several mechanisms: (1) B cell depletion, (2) interruption of B-T cell interaction via the CD40-CD154 costimulatory pathway, (3) restoration of immune tolerance to TSH-R, and (4) antagonism of TSH-R.

\section{Novel Treatment Approaches of GH (Table 1; Fig. 1)}

\section{Rituximab}

Rationale and Mechanisms of Action. Rituximab (RTX) is a chimeric murine/human monoclonal antibody targeting CD20 antigen, causing rapid depletion of B cells (from the stage of pre-B cells to mature and memory $\mathrm{B}$ cells as well as short-lived plasma cells) in peripheral and lymphoid organs [13]. It is believed that RTX dampens B cell actions (e.g., antigen presentation, cytokine release) and reduces the production of pathogenic autoantibodies through elimination of plasma cell precursors.

Summary of Clinical Trials and Therapeutic Applications. In a nonrandomized pilot study [14], $20 \mathrm{GH}$ patients were rendered euthyroid after about 4 months of methimazole and then assigned to RTX $\left(375 \mathrm{mg} / \mathrm{m}^{2}\right.$ weekly for four doses) or observation alone. Four of 10 patients in the RTX group remained in remission with a median follow-up of 25 months, and they all had baseline TSH-R-Ab levels < 5 IU/L. Baseline TSH-R-Ab levels did not differ significantly between the treatment and control groups. In treatment group $4 / 10$ and in control group $5 / 10$ had a baseline TSH-R-Ab level $<5$ IU/L. All patients in the observation group, who had similar baseline TSH$\mathrm{R}-\mathrm{Ab}$ levels, eventually relapsed by 14 months. While the reduction in TSH-R-Ab levels was similar between the two groups, thyroid-stimulating immunoglobulin (TSI) activity as measured by a bioassay was reduced significantly only in RTX group [15].

In another single-arm phase 2 study [16], 13 patients with relapsing GH received two doses of RTX $1 \mathrm{~g}$ with a 2 -week interval. Nine patients (69\%) became euthyroid and remained in remission after a median follow-up of 18 months, and they all achieved significant reduction in TSH-R-Ab levels. The remain-ing 4 patients had persistent hyperthyroidism requiring RAI. An ongoing singlearm phase 2 trial conducted in the UK aims to determine whether the combination of a single dose of RTX (500 $\mathrm{mg}$ ) and a 12-month course of ATDs can improve the remission rate at 2 years in a group of young GH patients (trial registration number: ISRCTN20381716). However, RTX use and research in GH have not gained much enthusiasm in view of the high cost and risk of severe side effects, including serum sickness-like reactions, iridocyclitis, polyarthritis, and inflammatory bowel disease [17].

\section{ATX-GD-59}

Rationale and Mechanisms of Actions. Antigen-specific immunotherapy is an effective treatment for common allergic conditions, especially atopy (allergic rhinitis/conjunctivitis, asthma, atopic dermatitis) and stinging insect hypersensitivity. It typically involves administration of the culprit allergen (or antigen) at gradually increasing quantities until the induction of the desired immune tolerance [18]. This strategy can also prove to be diseasemodifying in autoimmune diseases by reinstating immune tolerance to autoantigens through administering
Lee/Kahaly 
Table 1. Key clinical studies on novel treatment approaches of GH

\begin{tabular}{|c|c|c|c|c|}
\hline $\begin{array}{l}\text { Therapeutics } \\
\text { [ref.] }\end{array}$ & Mechanism of action & Study design/patient population & Key findings & $\begin{array}{l}\text { Common/important } \\
\text { toxicities }\end{array}$ \\
\hline RTX [14] & B cell depletion & $\begin{array}{l}\text { - Prospective, controlled, } \\
\text { nonrandomized study } \\
20 \text { patients with untreated GH, } \\
\text { rendered euthyroid after } \sim 4 \text { months } \\
\text { of methimazole, then withdrawn } \\
\text { - Intervention: } \\
\rightarrow 10 \text { RTX group (i.v. RTX } 375 \mathrm{mg} / \\
\mathrm{m}^{2} \text { weekly for } 4 \text { doses) } \\
\rightarrow 10 \text { control group (observation } \\
\text { alone) }\end{array}$ & $\begin{array}{l}\text { - } 4 / 10(40 \%) \text { in RTX group } \\
\text { remained in remission with } \\
\text { median FU of } 25 \text { months } \\
\text { - } 10 / 10(100 \%) \text { in control group } \\
\text { relapsed by } 14 \text { months }\end{array}$ & \multirow[t]{2}{*}{$\begin{array}{l}\text { Serum sickness-like } \\
\text { reactions; iridocyclitis; } \\
\text { polyarthritis; inflammatory } \\
\text { bowel disease }\end{array}$} \\
\hline RTX [16] & B cell depletion & $\begin{array}{l}\text { - Prospective, single-arm, phase } 2 \\
\text { study } \\
\text { - } 13 \text { patients with relapsing GH } \\
\text { - Intervention: } 2 \text { doses of i.v. RTX } 1 \mathrm{~g} \\
\text { with a 2-week interval }\end{array}$ & $\begin{array}{l}\text { - } 9 / 13(69 \%) \text { euthyroid and } \\
\text { remained in remission after a } \\
\text { median FU of } 18 \text { months (all } \\
\text { responders achieved significant } \\
\text { reduction in TSH-R-Ab levels) }\end{array}$ & \\
\hline Iscalimab [26] & $\begin{array}{l}\text { Anti-CD } 40 \text { MAb blocking } \\
\text { the CD } 40 \text {-CD } 154 \\
\text { costimulatory } \\
\text { pathway }\end{array}$ & $\begin{array}{l}\text { Open-label, phase } 2 \text {, single-arm, } \\
\text { proof-of-concept study } \\
\text { - } 15 \text { patients with untreated GH } \\
\text { Intervention: } 5 \text { doses of i.v. } \\
\text { iscalimab }(10 \mathrm{mg} / \mathrm{kg}) \text { over } 12 \text { weeks }\end{array}$ & $\begin{array}{l}\text { - } 7 / 15 \text { (47\%) euthyroid by week } \\
24,4 / 7(57 \%) \text { responders } \\
\text { relapsed by week } 36 \\
\text { - Marked reduction in TSH-R-Ab } \\
\text { levels, } 4 / 15(27 \%) \text { achieved } \\
\text { normal TSH-R-Ab levels by } \\
\text { week } 20\end{array}$ & Nil \\
\hline
\end{tabular}

FU, follow-up; GH, Graves' hyperthyroidism; i.v., intravenous; MAb, monoclonal antibody; RTX, rituximab; TSH-R, thyrotropin receptor; TSH-R-Ab, thyrotropin receptor autoantibody; TSI, thyroid-stimulating immunoglobulin.

synthetic peptides ("apitopes," i.e., antigen-processing independent epitopes) that mimic naturally processed CD4+ T cell epitopes. Apitopes comprising proinsulin peptides and myelin basic protein peptides have already shown clinical efficacy in type 1 diabetes (phase $1 \mathrm{~b}$ study [19]) and multiple sclerosis (phase 2a study [20]), respectively. A mixture of two immunodominant apitopes based on the sequence of human TSH-R (ATX-GD-59) was sufficient to suppress both the T-cell and TSH-R-Ab response when administered in soluble form to HLA-DR3 transgenic mice immunized with human TSH-R [21].

Summary of Clinical Trials and Therapeutic Applications. The safety and biological activity of ATX-GD-59 in untreated adult GH patients were evaluated in an openlabel, phase 1, single-arm study [22]. Ten subjects re- ceived all ten doses of intradermal ATX-GD-59 over 18 weeks, followed by 12 weeks of follow-up. Five achieved normalization of fT 3 levels and 2 had reduction in serum fT3/fT4 levels by week 18, making a complete or partial response rate of $70 \%$. Three complete responders remained relapse-free for 1 year after the last dose of study drug. Reductions in serum fT4 and fT3 levels were significantly correlated with reductions in both TSH-R-Ab and TSI levels. ATX-GD-59 was generally well tolerated. Mild injection site reactions accounted for the majority (85\%) of treatment-related side effects. Antigen-specific immunotherapy is an attractive therapeutic option in $\mathrm{GH}$ due to the absence of generalized immunosuppression. Future studies will explore its potential to achieve safe and effective long-term cure of $\mathrm{GH}$. 


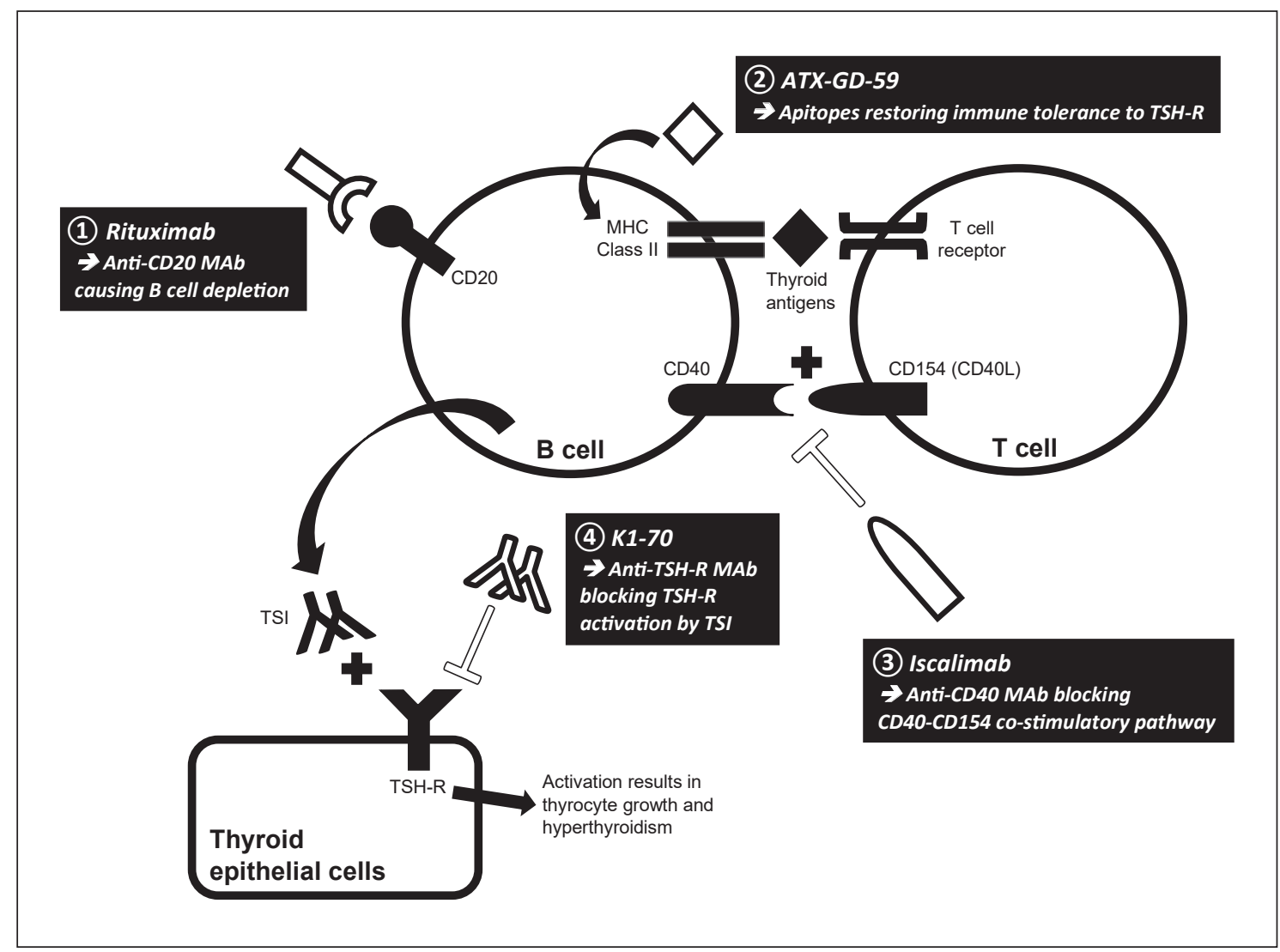

Fig. 1. Sites of action of novel treatments for GH. CD40L, CD40 ligand; GH, Graves' hyperthyroidism; MAb, monoclonal antibody; MHC Class II, major histocompatibility complex class II molecule; TSH-R, thyrotropin receptor; TSI, thyroid-stimulating immunoglobulin.

\section{Iscalimab (CFZ533)}

Rationale and Mechanisms of Action. The breakdown of immune tolerance towards thyroid antigens generates autoreactive CD4+ helper T cells against TSH-R. T cell receptors interact with major histocompatibility complex class II molecules of antigen-presenting cells (primarily B cells) through which TSH-R peptides are presented. The interaction is followed by synthesis and presentation of CD154 (CD40 ligand) on T cells, which binds to CD40 on B cells, leading to costimulation of $\mathrm{B}$ cells. The CD40-CD154 costimulatory pathway is essential for $\mathrm{T}$ cell-dependent humoral immune response and plays an important role in the pathogenesis of $\mathrm{GH}$ by promoting autoreactive $\mathrm{B}$ cell activation, intrathyroidal germinal center function, and TSH-R-Ab production. CD40 expression in thyroid tissue from GH patients was stronger than that in non-GH samples. CD40 agonist promoted thyroid tissue proliferation, thyroid hormone synthesis, and thyroglobulin secretion in vitro [23]. Iscalimab is an Fc-silenced (nondepleting), fully human, pathway-blocking anti-CD40 monoclonal antibody. It inhibited CD154-induced activation of human leukocytes in vitro. Animal studies showed that it blocked primary and recall $\mathrm{T}$ cell-dependent antibody responses in nonhuman primates and abrogated germinal center formation without depleting peripheral B cells. Prolonged renal allograft survival in cynomolgus monkeys was also demonstrated [24]. Preliminary results from two phase 2a trials have demonstrated efficacy of iscalimab in Sjögren syndrome [25]. Therefore, blocking CD40 is potentially useful in $\mathrm{GH}$.

Summary of Clinical Trials and Therapeutic Applications. The safety and efficacy of iscalimab in GH was examined in a recent phase 2 , single-arm, proof-of-concept trial [26]. Fifteen $\mathrm{GH}$ patients received five doses of intravenous iscalimab over 12 weeks, followed by a 24 -week 
follow-up. Complete CD40 engagement was achieved for up to 20 weeks. Seven of 15 patients (47\%) attained biochemical euthyroidism by week 24 . All patients with a baseline TSH-R-Ab $<20$ IU/L were responders. Four of 7 responders (57\%) developed relapse by week 36 . Nonresponders tended to have higher clinical scores (based on pretreatment age, goiter size, as well as fT4 and TSH-R$\mathrm{Ab}$ levels), which predicted recurrence of $\mathrm{GH}$ after a course of ATDs [27]. Iscalimab also resulted in marked reduction in TSH-R-Ab levels $(\sim 40 \%$ at week 12 and $\sim 70 \%$ at week 20 ). Four of 15 patients (27\%) achieved normalization of TSH-R-Ab by week 20 . Iscalimab was generally well tolerated without major safety signals. Further investigations of iscalimab in $\mathrm{GH}$ are warranted in view of its promising preliminary results. Indeed, multiple ongoing trials are also investigating the role of iscalimab in various immunological conditions, including systemic lupus erythematosus, lupus nephritis, rheumatoid arthritis, myasthenia gravis, and solid organ transplantations.

\section{TSH-R Small-Molecule Ligands}

Rationale and Mechanisms of Action. Blocking the activation of TSH-R by TSI represents the most direct strategy to treat GH. Several small-molecule substances have been reported to prevent TSH-R activation in vitro. NIDDK/ CEB-52, a TSH-R antagonist, selectively inhibited TSH-R activation by both TSH and TSH-R-Ab from GH patients [28]. The same group also developed TSH-R inverse agonists (NCGC00161856, NCGC00229600) which inhibited TSH-R signaling (in terms of cAMP production) and upregulation of mRNA transcripts for thyroglobulin, thyroperoxidase, sodium iodide symporter, and TSH-R $[29,30]$. Org 274179-0, a potent allosteric TSH-R antagonist, completely inhibited TSH and TSI-mediated TSH-R activation at nanomolar concentrations [31]. NCGC00242364 (ANTAG3), an analog of the previously mentioned inverse agonist NCGC00161856, effectively reduced serum fT4 level and mRNAs for sodium iodide symporter/thyroperoxidase in mice treated with thyrotropin-releasing hormone or human thyroid-stimulating monoclonal antibody M22 [32]. S37a was a recently discovered highly selective small-molecule TSH-R antagonist which inhibited TSH-R activation by TSH and M22 [33].

\section{TSH-R-Blocking Antibody}

In 2010, the human TSH-R-blocking monoclonal antibody K1-70 was isolated from a patient with a high TSH-R-Ab level who initially presented with hyperthyroidism followed by hypothyroidism [34]. A subse- quent in vivo study demonstrated that $\mathrm{K} 1-70$ resulted in a dose-dependent reduction in fT4 levels and inhibited the stimulating effect of M22 on fT4 levels in rats [35]. An ongoing phase 1 open-label trial is now examining the safety, tolerability, pharmacokinetics, and pharmacodynamics of a single dose of K1-70 (intramuscular injection or intravenous infusion) administered to patients with GH (ClinicalTrials.gov: NCT02904330).

\section{GO: Limitations of Current Therapy}

The major pathological processes of GO include intraorbital inflammatory infiltration, release of various inflammatory molecules (e.g., proinflammatory cytokines, chemoattractants, adhesion molecules, growth factors, etc.), and autoantibodies targeting TSH-R (and possibly insulin-like growth factor 1 receptor [IGF-1R]), as well as activation of orbital fibroblasts which are the key effector cells. Orbital fibroblasts not only proliferate and differentiate into myofibroblasts and adipocytes (de novo adipogenesis), but also produce excessive hydrophilic glycosaminoglycans. The resultant expansion of orbital tissue volume and elevated intraorbital pressure have mechanical consequences which explain the typical signs and symptoms of GO [36]. Intravenous GCs (IVGCs) are a disease modifier and the mainstay of treatment for active moderate-to-severe and/or sight-threatening GO (dysthyroid optic neuropathy [DON]) [2]. Previous treatment with IVGC reduces the number of required rehabilitative surgeries thereafter. However, approximately $20-30 \%$ of patients with active moderate-to-severe GO may not respond to IVGC or may develop disease reactivation after steroid withdrawal [2]. IVGC markedly improves disease activity, but is less effective in ameliorating severity parameters, e.g., proptosis, ocular dysmotility, and diplopia [37]. Residual functional impairment, the requirement of rehabilitative surgery, and associated impaired qualify of life may therefore persist despite current therapies. The morbidity and mortality rates of IVGC were 6.5 and $0.6 \%$, respectively according to a review of 14 studies involving $>1,000$ GO patients. Cardiovascular or cerebrovascular complications, hepatotoxicity, and fatal acute liver failure occurred if high single $(>0.75 \mathrm{~g}) /$ cumulative doses $(>8 \mathrm{~g}$ ) or a consecutive-day regimen were given $[2,37]$. New treatment strategies of GO focus on targeting lymphocytic infiltration, proinflammatory cytokines, IGF-1R, and orbital fibroblasts. 
Table 2. Key RCTs on novel treatment approaches of GO

\begin{tabular}{|c|c|c|c|c|}
\hline $\begin{array}{l}\text { Therapeutics } \\
\text { [ref.] }\end{array}$ & $\begin{array}{l}\text { Mechanism of } \\
\text { action }\end{array}$ & $\begin{array}{l}\text { Study design/ } \\
\text { patient population }\end{array}$ & Key outcomes & $\begin{array}{l}\text { Results (intervention vs. } \\
\text { control group) }\end{array}$ \\
\hline MMF [48] & $\begin{array}{l}\text { Dual } \\
\text { antiproliferative } \\
\text { effect on both B } \\
\text { and T cells }\end{array}$ & $\begin{array}{l}\text { - Single-center RCT } \\
\text { - } 174 \text { euthyroid patients with } \\
\text { active moderate-to-severe GO } \\
\text { - MMF } 1 \text { g daily vs. GC therapy } \\
\text { (both for } 24 \text { weeks) }\end{array}$ & $\begin{array}{l}\text { Primary } \\
\text { - Response rates at weeks } 12 \text { and } 24 \\
\text { (improvement in } \geq 3 \text { parameters of the } \\
\text { composite index without deterioration in } \\
\text { any objective parameters) }\end{array}$ & $\begin{array}{l}\text { - Week } 12: 79 \text { vs. } 51 \% \\
\text { Week } 24: 91 \text { vs. } 68 \%\end{array}$ \\
\hline TPТ $[94,95]$ & $\begin{array}{l}\text { Anti-IGF-1R- } \\
\text { blocking MAb }\end{array}$ & $\begin{array}{l}\text { - Two multicenter RCTs } \\
\text { - } 170 \text { euthyroid patients with } \\
\text { active moderate-to-severe GO } \\
\text { in total } \\
\text { - TPT (once every } 3 \text { weeks for } \\
8 \text { i.v. infusions; first dose } \\
10 \mathrm{mg} / \mathrm{kg} \text {, remaining } 7 \text { doses } \\
20 \mathrm{mg} / \mathrm{kg} \text { ) }\end{array}$ & $\begin{array}{l}\text { - Overall responders (reduction of } \geq 2 \text { points } \\
\text { in CAS and reduction of } \geq 2 \mathrm{~mm} \text { in } \\
\text { proptosis) at week } 24 \\
\text { - CAS of } 0 \text { or } 1 \\
\text { - Reduction of } \geq 2 \mathrm{~mm} \text { in proptosis } \\
\text { - Diplopia response } \\
\text { - GO-QoL scales }\end{array}$ & $\begin{array}{l}\text { - } 73 \text { vs. } 14 \% \\
\text { - } 62 \text { vs. } 22 \% \\
\text { - } 77 \text { vs. } 15 \% \\
\text { - } 68 \text { vs. } 27 \% \\
\text { - TPT group reported higher scores } \\
\text { and greater improvement in overall } \\
\text { visual functioning and appearance } \\
\text { scores }\end{array}$ \\
\hline
\end{tabular}

CAS, clinical activity score; GC, glucocorticoid; GO, Graves’ orbitopathy; GO-QoL, Graves’ orbitopathy-specific quality of life; i.v., intravenous; IGF-1R, insulin-like growth factor 1 receptor; IL-6R, interleukin 6 receptor; IVGC, intravenous glucocorticoid; MAb, monoclonal antibody; MMF, mycophenolate mofetil; MPS, mycophenolate sodium; RCT, randomized controlled trial; RTX, rituximab; TCZ, tocilizumab; TPT, teprotumumab. 


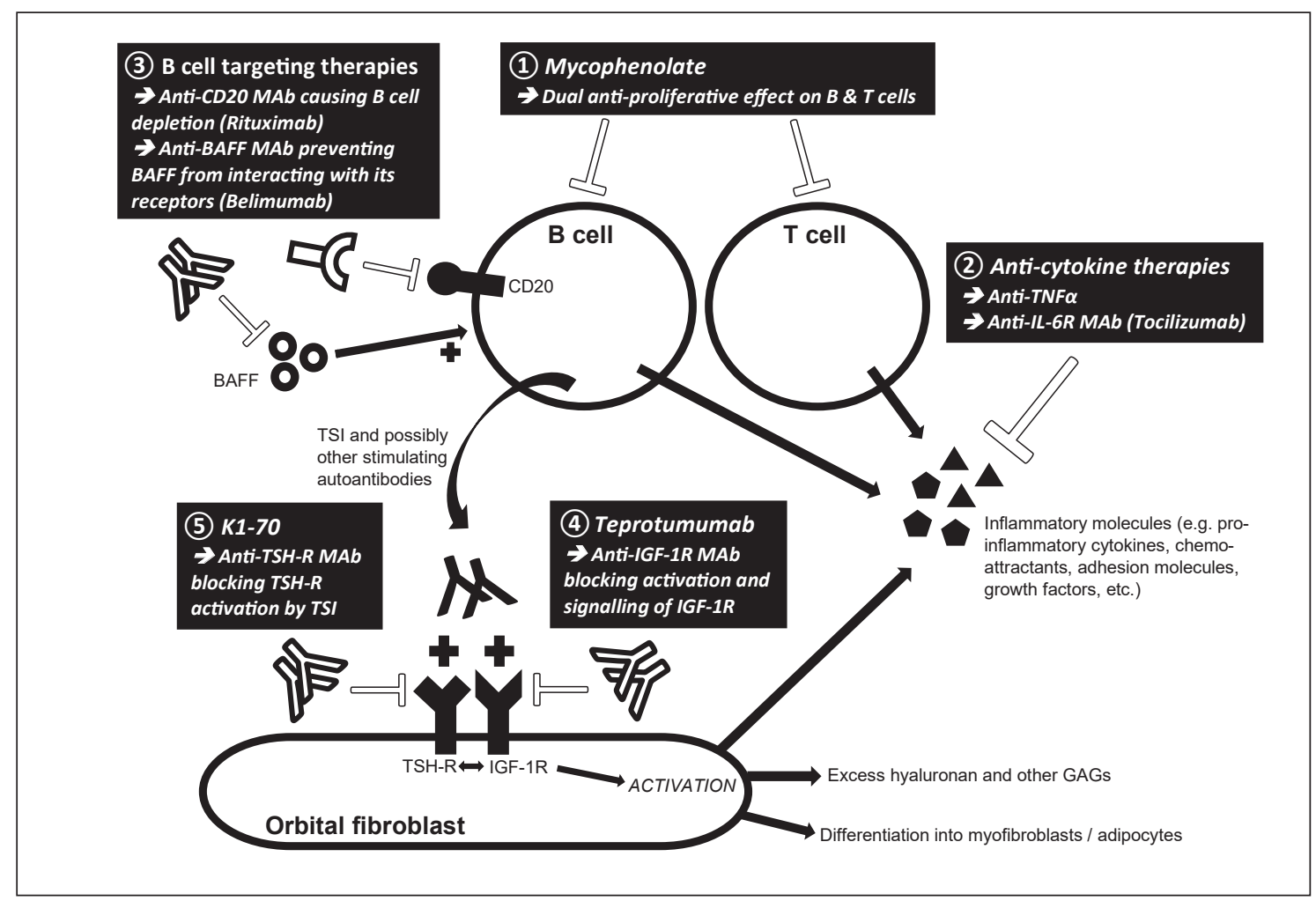

Fig. 2. Sites of action of novel treatments for GO. BAFF, B cell-activating factor; GAGs, glycosaminoglycans; GO, Graves' orbitopathy; IGF-1R, insulin-like growth factor 1 receptor; IL-6R, interleukin 6 receptor; MAb, monoclonal antibody; TNFa, tumor necrosis factor alpha; TSH-R, thyrotropin receptor; TSI, thyroid-stimulating immunoglobulin.

\section{Novel Treatment Approaches of GO (Table 2; Fig. 2)}

\section{Mycophenolate}

Rationale and Mechanisms of Actions. Activated lymphocytes rely on de novo synthesis of guanosine nucleotides, in which the rate-limiting step is catalyzed by inosine monophosphate dehydrogenase (IMPDH). Unlike other cell types, lymphocytes are unable to produce guanosine nucleotides via the salvage pathway. Mycophenolic acid (MPA) competitively and reversibly inhibits IMPDH, resulting in decreased antibody production by B cells as well as dual antiproliferative effect on both B and T cells. MPA also induces apoptosis of activated $\mathrm{T}$ cells and inhibits expression of adhesion molecules and recruitment of immune cells [38]. In addition, in vitro studies suggested that mycophenolate possessed antifibrotic capability by inhibiting fibroblast proliferation [39-42] and functions (e.g., collagen deposition $[39,42,43]$, interleukin 6 [IL-6] production [44]) via both IMPDH-dependent and -independent pathways $[40,42]$. Inhibition of the PI3K/mTOR signaling pathway in human orbital preadipocytes/fibroblasts decreased hyaluronan accumulation and adipogenesis [45], and mycophenolate has recently been shown to inhibit the same pathway in a rat model of epilepsy [46]. Mycophenolate represents an attractive therapeutic agent because it targets both lymphocytes and possibly orbital fibroblasts, which are the key players in the pathogenesis of GO. MPA is available worldwide as mycophenolate mofetil (MMF) and/or entericcoated mycophenolate sodium.

Summary of Clinical Trials and Therapeutic Applications. A Chinese case series first reported the efficacy of MMF in GO in 2004 [47]. The same group performed the first single-center randomized controlled trial to further evaluate the efficacy and safety of mycophenolate in GO ("Chinese trial" [48]). A total of 174 euthyroid patients with active moderate-to-severe $\mathrm{GO}$ were randomized to GC or MMF $1 \mathrm{~g}$ daily, both for 24 weeks. The primary endpoint was overall response at week 12 and 
24, which was defined as improvement in at least three parameters in the composite index (clinical activity score [CAS], soft tissue involvement, proptosis, eye movement, diplopia, and visual acuity). The MMF group demonstrated a superior overall response rate (78.8\%/91.25\% at week $12 / 24$ vs. $51.3 \% / 67.9 \%$ in the GC group). Disease inactivation was observed in $93.8 \%$ of the MMF group (vs. $69.2 \%$ in the GC group) at week 24 . MMF also performed better in most other parameters in the composite outcome, including soft tissue involvement, proptosis, and diplopia. Six percent of patients in the GC group developed disease reactivation during the study period, while none in the MMF group relapsed.

Subsequently, the European Group on Graves' Orbitopathy (EUGOGO) multicenter randomized controlled trial further characterized the role of mycophenolate in GO [49]. A total of 164 euthyroid patients with active moderate-to-severe $\mathrm{GO}$ were randomized to standard weekly IVGC for 12 weeks or a combination of IVGC for 12 weeks and mycophenolate sodium $720 \mathrm{mg}$ daily for 24 weeks (equivalent MPA content as MMF $1 \mathrm{~g}$ daily). The prespecified primary endpoints were response rate at week 12 (improvement in at least two parameters of a composite ophthalmic index comprising CAS, eyelid swelling, proptosis, lid width, eye muscle motility, and diplopia) and relapse rates at weeks 24/36. Post hoc outcomes included response rate at week 24 and sustained response at week 36. Although the primary endpoints were not met, the combination group displayed superior response rate at week 24 (71 vs. 53\%) and sustained response rate at week 36 (67 vs. 43\%). Post hoc analysis showed that the combination group demonstrated more significant improvement in CAS, swelling of eyelids or caruncle, orbital pain, chemosis, downgaze duction and elevation, as well as visual functioning subscale in the GO-specific quality of life (GO-QoL) questionnaire. Although a direct comparison between the two trials is not possible, several important differences in baseline characteristics between the two study populations (higher mean age, more prevalent smoking, longer disease duration, and greater proportion of TSH$\mathrm{R}-\mathrm{Ab}$ positive patients) may explain the lower response rates in the EUGOGO trial [50].

The safety data of mycophenolate in GO from both trials were also systemically analyzed [50]. Adverse events and serious adverse events were more common in the combination group of the EUGOGO trial than in the MMF group of the Chinese trial. None of the serious adverse events was a treatment-related side effect. Most side effects in the combination group were mild. Gastro- intestinal intolerance was slightly more prevalent among mycophenolate-treated patients. The combination treatment did not heighten the risk of infection and hepatotoxicity when compared to GC monotherapy. Both trials did not report any case of cytopenia, serious infection, or treatment-related mortality. The fact that mycophenolate trials in other autoimmune diseases or transplantations displayed much higher adverse event rates suggested that mycophenolate toxicities were mostly dose- and duration-dependent. Hence, the combination of low-dose 6-month mycophenolate and IVGC, both safe and affordable, can be considered as the first-line treatment of active moderate-to-severe GO in view of its superior efficacy compared to the current standard of care.

\section{Anti-Tumor Necrosis Factor Alpha Therapy}

Rationale and Mechanisms of Action. The level of tumor necrosis factor alpha (TNFa) was found to be elevated in the serum [51], tears [52], and orbital tissues [53] of GO patients compared to controls. TNF $\alpha$ stimulated the expression of adhesion molecules and hyaluronan production in orbital fibroblasts, but these actions were inhibited by anti-TNFa agents [54]. Adalimumab, an antiTNFa agent, was shown to reduce IL-6 production in GO orbital fibroblasts [55]. Under combined stimulation with TNFa and interferon gamma, GO orbital fibroblasts overexpressed B cell-activating factor which promoted B cell survival [53].

Summary of Clinical Trials and Therapeutic Applications. The efficacy of selected anti-TNFa agents in GO was described in several case reports [56-58]. A prospective nonrandomized trial reported the use of etanercept (25 mg twice weekly for 12 weeks) in 10 patients with active GO [59]. Although 6 patients $(60 \%)$ reported moderate to marked improvement, 3 of them relapsed at the end of treatment. In a small retrospective study, adalimumab (one 80-mg injection followed by biweekly 40 -mg injections) was given to $10 \mathrm{GO}$ patients who were either steroid-unresponsive or -intolerant. Clinical improvement was observed only in those with a high baseline inflammatory index [60]. The role of anti-TNFa has not been further evaluated in randomized controlled trials, probably because of its limited efficacy.

\section{Rituximab}

Rationale and Mechanisms of Action. Apart from peripheral $\mathrm{B}$ cell depletion, complete (or near complete) intraorbital depletion of both B and T cells after RTX therapy has been confirmed in multiple reports [36]. Since the 
clinical improvement of GO after RTX is not consistently correlated with the reduction in serum TSH-R-Ab, the efficacy of RTX is probably explained by elimination of other B cell functions beside autoantibody production (e.g., cytokine production, antigen presentation, B-T cell costimulation, etc.) [13].

Summary of Clinical Trials and Therapeutic Applications. Two randomized controlled trials examined the efficacy of RTX in patients with active moderate-to-severe $\mathrm{GO}$, but they generated grossly conflicting outcomes. The Italian trial [61] compared RTX ( $1 \mathrm{~g}$ twice at a 2-week interval or single dose of $500 \mathrm{mg}$ ) with weekly IVGC (12 doses, cumulative dose $7.5 \mathrm{~g}$ ). All patients in the RTX group achieved disease inactivation at week 24 (68.7\% in the IVGC group) and none developed reactivation $(31.2 \%$ in the IVGC group). Patients in the RTX group also attained better ocular motility and required less rehabilitative surgical procedures up to 18 months after treatment. However, the US trial [62] found that RTX did not offer additional benefit over placebo in terms of CAS and other secondary endpoints. A subsequent joint post hoc analysis suggested that several differences in baseline characteristics (younger age, lower TSH-R-Ab, shorter duration of GO) may explain the favorable treatment outcomes in the Italian trial [63]. In fact, B cell infiltration was absent in some immunohistochemically analyzed GO orbital tissues [36], and this might explain why some patients failed to respond to RTX. A recent French retrospective series also found limited efficacy of RTX in steroid-refractory active moderate-to-severe $\mathrm{GO}$ with long disease duration (median 26 months) [64]. A few patients in the RTX groups of both randomized trials developed a transient increase in proptosis or visual loss, and 2 patients even developed frank DON. It is postulated that massive lysis of intraorbital B cells due to RTX therapy may cause cytokine release syndrome with subsequent edema and expansion of orbital tissue, leading to progression of subclinical or impending DON [63]. Based on the latest evidence, the EUGOGO recommends that RTX be considered as one of the second-line treatment options after failure of IVGC, but it should not be used in patients with impending DON or long duration of disease [2]. B cell-activating factor plays an important role in promoting B cell survival and maturation as well as autoantibody production [13]. An ongoing randomized trial is now comparing belimumab (a fully human IgG1 anti-B cellactivating factor monoclonal antibody) with IVGC in the management of active GO and GH (EudraCT: 2015002127-26). The final analysis of the trial is expected to be available soon.

Novel Treatments for Graves'

Hyperthyroidism and Orbitopathy

\section{Tocilizumab}

Rationale and Mechanisms of Action. IL-6 is a potent proinflammatory cytokine implicated in the pathogenesis of various autoimmune diseases such as rheumatoid arthritis, multiple sclerosis, and systemic lupus erythematosus. Activation of GO orbital fibroblasts led to the production of multiple chemoattractants including IL-6 [65, 66]. TSH-R activation (by TSH or M22) increased IL-6 expression in GO orbital preadipocytic fibroblasts and mature adipocytes [67]. IL-6 supported B cell differentiation and synthesis of autoantibodies [68]. It also stimulated the expression of TSH-R in GO orbital fibroblasts [69]. IL-6 suppressed regulatory $\mathrm{T}$ cell induction while promoting the development and functions of Th17 cells, a recently identified CD4+ $\mathrm{T}$ cell subset which plays an important pathogenic role in GO [70-72]. Higher serum levels of IL- 6 were noted in GD patients with GO than in those without GO [73]. Greater lacrimal levels of IL-6 were also shown in GO patients compared to healthy controls, and they positively correlated with CAS $[52,74]$. Therefore, blocking the IL- 6 pathway by tocilizumab (TCZ), a fully human IgG1 anti-IL-6 receptor monoclonal antibody, represents a sound strategy in GO.

Summary of Clinical Trials and Therapeutic Applications. Multiple preliminary reports have described the efficacy of TCZ in GO, especially when refractory to conventional treatments [75-79]. Interestingly, orbital fat biopsy performed in a case of severe GO after TCZ therapy revealed complete absence of inflammatory infiltrates [76]. A small randomized controlled trial investigated the efficacy of TCZ in patients with GC-resistant active moderate-to-severe GO [80]. Thirty-two patients were randomized to TCZ ( $8 \mathrm{mg} / \mathrm{kg}$ intravenously once every 4 weeks for four doses) or placebo; 93.3 and $86.7 \%$ in the TCZ group showed improvement in CAS by at least $2 / 10$ at week 16 and week 40, respectively (vs. 59\% in the placebo group at both weeks). A CAS of $<3 / 10$ was achieved in 86.7 and $80 \%$ in the TCZ group at week 16 and week 40 , respectively (vs. 35.2 and $47.1 \%$ in the placebo group). A greater proportion of patients in the TCZ group demonstrated improvement in the EUGOGO-proposed composite ophthalmic score, which was driven mainly by improvements in soft tissue involvement and CAS. However, TCZ did not offer significant benefit in terms of proptosis and diplopia. The relatively high response rate in the placebo group may be explained by previous IVGC therapy or spontaneous improvement along Rundle's curve. The potent anti-inflammatory effect of TCZ in active GO appears promising, although this trial was limited by its small sample size and the arbitrary definitions

Eur Thyroid J 2020;9(suppl 1):17-30 DOI: $10.1159 / 000508789$ 
of GC resistance (CAS improvement of $<2 / 10$ after at least three doses of weekly IVGC or increase in CAS of at least $1 / 10$ after treatment with IVGC). Indeed, as many as $60 \%$ of patients with active GO who appeared unresponsive after six doses of weekly IVGC may still improve later in terms of CAS [81]. TCZ is overall safe and well tolerated. Larger trials will be needed in the future to precisely define its role in the management of GO.

\section{Teprotumumab}

Rationale and Mechanisms of Action. IgG from patients with GD (GD-IgG) was able to displace insulin-like growth factor 1 (IGF-1) from the binding sites of IGF-1R $[82,83]$ on the surface of orbital fibroblasts. IGF-1R was overexpressed in GO orbital fibroblasts [84] and lymphocytes $[85,86]$. IGF-1R formed a physical and functional complex with TSH-R, and its activity was important for mediating TSH-R downstream signaling [87]. IGF-1R autoantibodies exist in both normal subjects and GD patients with or without GO $[88,89]$, although it remains highly controversial whether they directly activate IGF$1 \mathrm{R}$ mediating the pathogenesis of GO $[87,88,90,91]$. Nevertheless, IGF-1R-blocking monoclonal antibody has been shown to inhibit the induction of $\mathrm{T}$ cell chemoattractants in orbital fibroblasts by GD-IgG/IGF-1 [83], reduced IGF-1R and TSH-R surface display on fibrocytes [92], and inhibited TSH/M22-induced expression of proinflammatory cytokines (IL-6, IL-8, TNF $\alpha$ ) in fibrocytes $[92,93]$. In vitro evidence therefore suggests that antagonizing IGF-1R is potentially beneficial in GO. Teprotumumab (TPT) is a fully human IgG1 monoclonal blocking antibody which binds to the extracellular portion of IGF-1R and blocks its activation and signaling by endogenous ligands (IGF-1 and IGF-2). Binding of TPT also leads to internalization and degradation of IGF-1R resulting in up to $95 \%$ reduction in accessible receptor protein on the cell surface [87]. TPT was initially designed as an anticancer therapy, but its development program was discontinued in 2009 for commercial reasons. TPT was subsequently repurposed for potential use in GO based on preclinical data.

Summary of Clinical Trials and Therapeutic Applications. The safety and efficacy of TPT was evaluated sequentially in two randomized, placebo-controlled multicenter trials which comprised a total of 170 patients with active moderate-to-severe GO $[94,95]$. Both trials had similar designs and patients were randomly assigned to TPT ( 83 patients; once every 3 weeks intravenously for 8 doses over 24 weeks) or placebo (87 patients). The primary endpoint of the initial phase 2 study was a compos- ite of reduction of at least 2/7 in CAS and a reduction of at least $2 \mathrm{~mm}$ in proptosis at week 24 , whereas the subsequent phase 3 study only focused on reductions in proptosis as the primary outcome. The results of both trials are jointly summarized below. Seventy-three percent in the TPT groups (vs. 14\% in the placebo groups) were overall responders with both CAS and proptosis improvement. Individually, CAS of 0/1 (62 vs. $22 \%$ ) and proptosis response (77 vs. $15 \%$ ) were much more common in the TPT groups. Proptosis response occurred early at week 6 in most patients. The mean reduction in proptosis by week 24 ranged from 2.95 to $3.32 \mathrm{~mm}$ [96], which was comparable to that achieved by single-wall orbital decompression [97]. Forty percent of the TPT group (phase 2) even had a marked reduction of $4 \mathrm{~mm}$ in proptosis at week 24 . Twenty-one of 29 responders (72\%) in the TPT group (phase 2 study) were graded as having high response, meaning a reduction of at least $3 \mathrm{~mm}$ in proptosis and a reduction of at least 3/7 in CAS. Diplopia response was observed in almost $70 \%$ of TPT-treated patients, approximately 2.5 times more likely than in placebo-treated cases. Six TPT-treated patients in the phase 3 study underwent orbital imaging, all showing reduction in extraocular muscle volume, orbital fat volume, or both. The radiological improvements probably explained the remarkable clinical response in proptosis and diplopia. TPT treatment was also associated with significant improvement in GO-QoL score. No anti-TPT antibodies were detected in patients during TPT therapy. The efficacy of TPT was maintained in most responders up to 48 weeks of follow-up in the phase 2 study. Patients in the phase 3 study who did not have proptosis response or developed relapse during the 48-week follow-up period could enter an open-label extension study (OPTIC-X; ClinicalTrials.gov: NCT03461211) and received eight additional TPT infusions. The follow-up and extension studies are currently ongoing. TPT was generally well tolerated and most adverse events were mild to moderate in severity. The only side effect unequivocally related to TPT was hyperglycemia, which affected 7 of 84 TPTtreated patients $(8.3 \%)$. It mainly affected patients with preexisting diabetes mellitus and was brought under control after adjusting diabetic medications.

TPT represents the first pharmacological treatment of GO which offers all-round efficacy (in terms of disease activity, severity, and quality of life) and a favorable safety profile. As a result, TPT has become the first drug approved by the US Food and Drug Administration for the treatment of adult GO since January 2020. Although there has been growing enthusiasm and heated debate on
26

Eur Thyroid J 2020;9(suppl 1):17-30 DOI: $10.1159 / 000508789$
Lee/Kahaly 
whether TPT will supersede systemic GC [98], its incorporation into routine clinical practice is limited by the lack of comprehensive long-term data, absence of headto-head comparison with IVGC, restricted geographical availability, and cost.

\section{Concluding Remarks}

The therapeutic potential of immunotherapies of GH is twofold: inducing durable remission of hyperthyroidism without thyroid ablation and treating GO simultaneously based on shared immunological mechanisms. ATX-GD-59 and iscalimab are particularly efficacious in patients with $\mathrm{GH}$ at low risk of relapse, but future trials on different dosing regimens will inform us whether those at medium to high risk of relapse will benefit as well. It is reasonable to recommend the combination of IVGC and mycophenolate as the updated standard of care in active moderate-to-severe GO in view of its practicability and superior efficacy to weekly IVGC monotherapy. Based on its success, other combinations of widely available and affordable therapies may also be beneficial in GO. An ongoing trial is investigating whether the addition of orbital radiotherapy to IVGC is superior to IVGC monotherapy (ClinicalTrials.gov: NCT02339142). In two respective case series, a UK group described a safe strategy of combining IVGC with RTX or methotrexate in active GO, which allowed reduced administration of steroids without compromising efficacy [99, 100]. Biologics (e.g., RTX, TCZ, TPT) hold great promise in future management of $\mathrm{GO}$ and can be useful if patients are intolerant or resistant to standard immunosuppressive treatment. However, they have not been vigorously tested against the current standard of care. The fact that they may not be widely available or affordable further adds to their limitations. As multiple pathogenic pathways are implicated in GO, several targeted therapies are worth exploring in clinical trials (e.g., anti-
IL-23 or anti-IL-17 for the IL-23/IL-17 axis; sirolimus for the mTOR pathway $[45,101,102])$. However, the process of developing and evaluating novel therapeutic agents is usually time-consuming and costly. Any novel therapeutic strategies in GO must be examined in randomized controlled trials before any conclusion regarding efficacy (i.e., proptosis and diplopia) and safety can be drawn. In addition, the outcome measure of GO trials should be a standardized composite index (comprising disease activity, severity, and quality of life assessment) which offers holistic assessment and facilitates comparisons among different studies. Therapeutic advances will continue to optimize our management of GH and GO in an effective and safe manner.

\section{Acknowledgement}

The editorial assistance of Miss Lara Frommer, MSc (Johannes Gutenberg University Thyroid Lab, Mainz, Germany) is appreciated.

\section{Conflict of Interest Statement}

The authors have no conflicts of interest to declare.

\section{Funding Sources}

The Johannes Gutenberg University Medical Center, Mainz, Germany has received research-associated funding from Novartis, USA, River Vision, USA, Horizon Therapeutics, USA, Quidel, USA, and Apitope, UK.

\section{Author Contributions}

G.J. Kahaly initiated the project. Literature search, preparation of tables, and drawing of figures were done by A.C.H. Lee. A.C.H. Lee and G.J. Kahaly wrote and critically reviewed the article.

\section{References}

1 Kahaly GJ, Bartalena L, Hegedüs L, Leenhardt L, Poppe K, Pearce SH. 2018 European Thyroid Association Guideline for the Management of Graves' Hyperthyroidism. Eur Thyroid J. 2018 Aug;7(4):167-86.

2 Bartalena L, Baldeschi L, Boboridis K, Eckstein A, Kahaly GJ, Marcocci C, et al.; European Group on Graves' Orbitopathy (EUGOGO) The 2016 European Thyroid Association/Eu- ropean Group on Graves' Orbitopathy Guidelines for the Management of Graves' Orbitopathy. Eur Thyroid J. 2016 Mar;5(1):9-26.

3 Dekkers OM, Horváth-Puhó E, Cannegieter SC, Vandenbroucke JP, Sørensen HT, Jørgensen JO. Acute cardiovascular events and all-cause mortality in patients with hyperthyroidism: a population-based cohort study. Eur J Endocrinol. 2017 Jan;176(1):1-9.
4 Kim HJ, Kang T, Kang MJ, Ahn HS, Sohn SY. Incidence and mortality of myocardial infarction and stroke in patients with hyperthyroidism: a nationwide cohort study in Korea. Thyroid. 2020 Jul;30(7):955-65.

5 Ponto KA, Hommel G, Pitz S, Elflein H, Pfeiffer N, Kahaly GJ. Quality of life in a German Graves orbitopathy population. Am J Ophthalmol. 2011 Sep;152(3):483-90.e1.
Novel Treatments for Graves'

Hyperthyroidism and Orbitopathy
Eur Thyroid J 2020;9(suppl 1):17-30 DOI: $10.1159 / 000508789$ 
6 Bruscolini A, Sacchetti M, La Cava M, Nebbioso M, Iannitelli A, Quartini A, et al. Quality of life and neuropsychiatric disorders in patients with Graves' Orbitopathy: current concepts. Autoimmun Rev. 2018 Jul;17(7): 639-43.

7 Ponto KA, Merkesdal S, Hommel G, Pitz S, Pfeiffer N, Kahaly GJ. Public health relevance of Graves' orbitopathy. J Clin Endocrinol Metab. 2013 Jan;98(1):145-52.

8 Brito JP, Payne S, Singh Ospina N, RodriguezGutierrez R, Maraka S, Sangaralingham LR, et al. Patterns of use, efficacy, and safety of treatment options for patients with Graves' disease: a nationwide population-based study. Thyroid. 2020 Mar;30(3):357-64.

9 Brix TH, Lund LC, Henriksen DP, Folkestad L, Bonnema SJ, Hallas J, et al. Methimazole and risk of acute pancreatitis. Lancet Diabetes Endocrinol. 2020 Mar;8(3):187-9.

10 Wiersinga WM, Duntas L, Fadeyev V, Nygaard B, Vanderpump MP. 2012 ETA Guidelines: The Use of L-T4 + L-T3 in the Treatment of Hypothyroidism. Eur Thyroid J. 2012 Jul;1(2):55-71.

11 Kahaly GJ, Diana T, Kanitz M, Frommer L, Olivo PD. Prospective Trial of Functional Thyrotropin Receptor Antibodies in Graves Disease. J Clin Endocrinol Metab. 2020 Apr; 105(4):105.

12 Kahaly GJ, Diana T, Olivo PD. TSH receptor antibodies: relevance \& utility. Endocr Pract. 2020 Jan;26(1):97-106.

13 Salvi M, Covelli D. B cells in Graves' Orbitopathy: more than just a source of antibodies? Eye (Lond). 2019 Feb;33(2):230-4.

14 El Fassi D, Nielsen CH, Bonnema SJ, Hasselbalch HC, Hegedüs L. B lymphocyte depletion with the monoclonal antibody rituximab in Graves' disease: a controlled pilot study. J Clin Endocrinol Metab. 2007 May;92(5): 1769-72.

15 El Fassi D, Banga JP, Gilbert JA, Padoa C, Hegedüs L, Nielsen $\mathrm{CH}$. Treatment of Graves' disease with rituximab specifically reduces the production of thyroid stimulating autoantibodies. Clin Immunol. 2009 Mar;130(3): 252-8.

16 Heemstra KA, Toes RE, Sepers J, Pereira AM, Corssmit EP, Huizinga TW, et al. Rituximab in relapsing Graves' disease, a phase II study. Eur J Endocrinol. 2008 Nov;159(5):609-15.

17 El Fassi D, Nielsen CH, Junker P, Hasselbalch HC, Hegedüs L. Systemic adverse events following rituximab therapy in patients with Graves' disease. J Endocrinol Invest. 2011 JulAug;34(7):e163-7.

18 Moote W, Kim H, Ellis AK. Allergen-specific immunotherapy. Allergy Asthma Clin Immunol. 2018 Sep;14(Suppl 2):53.

19 Alhadj Ali M, Liu YF, Arif S, Tatovic D, Shariff $\mathrm{H}$, Gibson VB, et al. Metabolic and immune effects of immunotherapy with proinsulin peptide in human new-onset type 1 diabetes. Sci Transl Med. 2017 Aug;9(402):9.
20 Chataway J, Martin K, Barrell K, Sharrack B, Stolt P, Wraith DC; ATX-MS1467 Study Group. Effects of ATX-MS-1467 immunotherapy over 16 weeks in relapsing multiple sclerosis. Neurology. 2018 Mar;90(11):e955-62.

21 Jansson L, Vrolix K, Jahraus A, Martin KF, Wraith DC. Immunotherapy with apitopes blocks the immune response to TSH receptor in HLA-DR transgenic mice. Endocrinology. 2018 Sep;159(9):3446-57.

22 Pearce SH, Dayan C, Wraith DC, Barrell K, Olive N, Jansson L, et al. Antigen-specific immunotherapy with thyrotropin receptor peptides in Graves' hyperthyroidism: a phase I study. Thyroid. 2019 Jul;29(7):1003-11.

23 Wang FM, Chen XM, Hao C, Tang HB, Shen $\mathrm{Q}, \mathrm{Xu} \mathrm{XY}$, et al. Costimulatory molecule CD40 expression in thyroid tissue of Graves' disease patients and its immune pathogenetic significance. Zhonghua Yi Xue Za Zhi. 2013 Mar;93(10):764-7. Chinese.

24 Ristov J, Espie P, Ulrich P, Sickert D, Flandre $\mathrm{T}$, Dimitrova $\mathrm{M}$, et al. Characterization of the in vitro and in vivo properties of CFZ533, a blocking and non-depleting anti-CD40 monoclonal antibody. Am J Transplant. 2018 Dec;18(12):2895-904.

25 Mavragani CP, Moutsopoulos HM. Sjögren's syndrome: old and new therapeutic targets. J Autoimmun. 2020 Jun;110:102364.

26 Kahaly GJ, Stan MN, Frommer L, Gergely P, Colin L, Amer A, et al. A novel anti-CD40 monoclonal antibody, iscalimab, for control of Graves hyperthyroidism - a proof-of-concept trial. J Clin Endocrinol Metab. 2020 Mar; 105(3): 105

27 Vos XG, Endert E, Zwinderman AH, Tijssen JG, Wiersinga WM. Predicting the Risk of Recurrence Before the Start of Antithyroid Drug Therapy in Patients With Graves' Hyperthyroidism. J Clin Endocrinol Metab. 2016 Apr; 101(4):1381-9.

28 Neumann S, Kleinau G, Costanzi S, Moore S, Jiang JK, Raaka BM, et al. A low-molecularweight antagonist for the human thyrotropin receptor with therapeutic potential for hyperthyroidism. Endocrinology. 2008 Dec; 149(12):5945-50.

29 Neumann S, Huang W, Eliseeva E, Titus S, Thomas CJ, Gershengorn MC. A small molecule inverse agonist for the human thyroidstimulating hormone receptor. Endocrinology. 2010 Jul;151(7):3454-9.

30 Neumann S, Eliseeva E, McCoy JG, Napolitano G, Giuliani C, Monaco F, et al. A new small-molecule antagonist inhibits Graves' disease antibody activation of the TSH receptor. J Clin Endocrinol Metab. 2011 Feb;96(2): 548-54.

31 van Koppen CJ, de Gooyer ME, Karstens WJ, Plate R, Conti PG, van Achterberg TA, et al. Mechanism of action of a nanomolar potent, allosteric antagonist of the thyroid-stimulating hormone receptor. Br J Pharmacol. 2012 Apr;165(7):2314-24.
32 Neumann S, Nir EA, Eliseeva E, Huang W, Marugan J, Xiao J, et al. A selective TSH receptor antagonist inhibits stimulation of thyroid function in female mice. Endocrinology. 2014 Jan;155(1):310-4.

33 Marcinkowski P, Hoyer I, Specker E, Furkert J, Rutz C, Neuenschwander M, et al. A New Highly Thyrotropin Receptor-Selective Small-Molecule Antagonist with Potential for the Treatment of Graves' Orbitopathy. Thyroid. 2019 Jan;29(1):111-23.

34 Evans M, Sanders J, Tagami T, Sanders P, Young S, Roberts E, et al. Monoclonal autoantibodies to the TSH receptor, one with stimulating activity and one with blocking activity, obtained from the same blood sample. Clin Endocrinol (Oxf). 2010 Sep;73(3):40412.

35 Furmaniak J, Sanders J, Young S, Kabelis K, Sanders P, Evans M, et al. In vivo effects of a human thyroid-stimulating monoclonal autoantibody (M22) and a human thyroidblocking autoantibody (K1-70). Auto Immun Highlights. 2011 Sep;3(1):19-25.

36 Hai YP, Lee AC, Frommer L, Diana T, Kahaly GJ. Immunohistochemical analysis of human orbital tissue in Graves' orbitopathy. J Endocrinol Invest. $2020 \mathrm{Feb}$;43(2):123-37.

37 Zang S, Ponto KA, Kahaly GJ. Clinical review: Intravenous glucocorticoids for Graves' orbitopathy: efficacy and morbidity. J Clin Endocrinol Metab. 2011 Feb;96(2):320-32.

38 Staatz CE, Tett SE. Pharmacology and toxicology of mycophenolate in organ transplant recipients: an update. Arch Toxicol. $2014 \mathrm{Jul}$; 88(7):1351-89.

39 Badid C, Vincent M, McGregor B, Melin M, Hadj-Aissa A, Veysseyre C, et al. Mycophenolate mofetil reduces myofibroblast infiltration and collagen III deposition in rat remnant kidney. Kidney Int. 2000 Jul;58(1):51-61.

40 Heinz C, Heise K, Hudde T, Steuhl KP. Mycophenolate mofetil inhibits human Tenon fibroblast proliferation by guanosine depletion. Br J Ophthalmol. 2003 Nov;87(11): $1397-8$

41 Azzola A, Havryk A, Chhajed P, Hostettler K, Black J, Johnson P, et al. Everolimus and mycophenolate mofetil are potent inhibitors of fibroblast proliferation after lung transplantation. Transplantation. 2004 Jan;77(2):275-80.

42 Petrova DT, Brandhorst G, Brehmer F, Gross O, Oellerich M, Armstrong VW. Mycophenolic acid displays IMPDH-dependent and IMPDH-independent effects on renal fibroblast proliferation and function. Ther Drug Monit. 2010 Aug;32(4):405-12.

43 Roos N, Poulalhon N, Farge D, Madelaine I, Mauviel A, Verrecchia F. In vitro evidence for a direct antifibrotic role of the immunosuppressive drug mycophenolate mofetil. J Pharmacol Exp Ther. 2007 May;321(2):583-9.

44 Miljkovic D, Samardzic T, Drakulic D, StosicGrujicic S, Trajkovic V. Immunosuppressants leflunomide and mycophenolic acid inhibit fibroblast IL- 6 production by distinct mechanisms. Cytokine. 2002 Aug;19(4):181-6. 
45 Zhang L, Grennan-Jones F, Draman MS, Lane C, Morris D, Dayan CM, et al. Possible targets for nonimmunosuppressive therapy of Graves' orbitopathy. J Clin Endocrinol Metab. 2014 Jul;99(7):E1183-90.

46 Mazumder AG, Patial V, Singh D. Mycophenolate mofetil contributes to downregulation of the hippocampal interleukin type 2 and $1 \beta$ mediated PI3K/AKT/mTOR pathway hyperactivation and attenuates neurobehavioral comorbidities in a rat model of temporal lobe epilepsy. Brain Behav Immun. 2019 Jan;75: 84-93.

47 Wang J, Wang YT, Shao JQ, Wang X, Du H. Immunosuppressive therapies in patients with Graves' ophthalmopathy. Zhonghua Nei Ke Za Zhi. 2004 Feb;43(2):125-7. Chinese.

48 Ye X, Bo X, Hu X, Cui H, Lu B, Shao J, et al. Efficacy and safety of mycophenolate mofetil in patients with active moderate-to-severe Graves' orbitopathy. Clin Endocrinol (Oxf). 2017 Feb;86(2):247-55.

49 Kahaly GJ, Riedl M, König J, Pitz S, Ponto K, Diana T, et al.; European Group on Graves' Orbitopathy (EUGOGO). Mycophenolate plus methylprednisolone versus methylprednisolone alone in active, moderate-to-severe Graves' orbitopathy (MINGO): a randomised, observer-masked, multicentre trial. Lancet Diabetes Endocrinol. 2018 Apr;6(4):287-98.

50 Lee AC, Riedl M, Frommer L, Diana T, Kahaly GJ. Systemic safety analysis of mycophenolate in Graves' orbitopathy. J Endocrinol Invest. 2020 Jun;43(6):767-77.

51 Wakelkamp IM, Gerding MN, Van Der Meer JW, Prummel MF, Wiersinga WM. Both Th1and Th2-derived cytokines in serum are elevated in Graves' ophthalmopathy. Clin Exp Immunol. 2000 Sep;121(3):453-7.

52 Kishazi E, Dor M, Eperon S, Oberic A, Turck N, Hamedani M. Differential profiling of lacrimal cytokines in patients suffering from thyroid-associated orbitopathy. Sci Rep. 2018 Jul;8(1):10792.

53 Tang F, Chen X, Mao Y, Wan S, Ai S, Yang H, et al. Orbital fibroblasts of Graves' orbitopathy stimulated with proinflammatory cytokines promote $B$ cell survival by secreting BAFF. Mol Cell Endocrinol. 2017 May;446: $1-11$.

54 Cawood TJ, Moriarty P, O'Farrelly C, O'Shea $D$. The effects of tumour necrosis factor-alpha and interleukin 1 on an in vitro model of thyroid-associated ophthalmopathy; contrasting effects on adipogenesis. Eur J Endocrinol. 2006 Sep;155(3):395-403.

55 van Steensel L, van Hagen PM, Paridaens D, Kuijpers RW, van den Bosch WA, Drexhage $\mathrm{HA}$, et al. Whole orbital tissue culture identifies imatinib mesylate and adalimumab as potential therapeutics for Graves' ophthalmopathy. Br J Ophthalmol. 2011 May;95(5):735-8.

56 Durrani OM, Reuser TQ, Murray PI. Infliximab: a novel treatment for sight-threatening thyroid associated ophthalmopathy. Orbit. 2005 Jun;24(2):117-9.
57 Komorowski J, Jankiewicz-Wika J, Siejka A, Lawnicka H, Kłysik A, Goś R, et al. Monoclonal anti-TNFalpha antibody (infliximab) in the treatment of patient with thyroid associated ophthalmopathy. Klin Oczna. 2007; 109(10-12):457-60.

58 Boskovic O, Medenica S, Radojevic N, Zarkovic M. Etanercept in the treatment of Graves' ophthalmopathy with primary hypothyroidism and rheumatoid arthritis. Cent Eur J Immunol. 2019;44(4):463-5.

59 Paridaens $\mathrm{D}$, van den Bosch WA, van der Loos TL, Krenning EP, van Hagen PM. The effect of etanercept on Graves' ophthalmopathy: a pilot study. Eye (Lond). 2005 Dec; 19(12):1286-9.

60 Ayabe R, Rootman DB, Hwang CJ, Ben-Artzi A, Goldberg R. Adalimumab as steroid-sparing treatment of inflammatory-stage thyroid eye disease. Ophthal Plast Reconstr Surg. 2014 Sep-Oct;30(5):415-9.

61 Salvi M, Vannucchi G, Currò N, Campi I, Covelli D, Dazzi D, et al. Efficacy of B-cell targeted therapy with rituximab in patients with active moderate to severe Graves' orbitopathy: a randomized controlled study. J Clin Endocrinol Metab. 2015 Feb;100(2):422-31.

62 Stan MN, Garrity JA, Carranza Leon BG, Prabin T, Bradley EA, Bahn RS. Randomized controlled trial of rituximab in patients with Graves' orbitopathy. J Clin Endocrinol Metab. 2015 Feb;100(2):432-41.

63 Lee AC, Riedl M, Frommer L, Diana T, Kahaly GJ. Systemic safety analysis of mycophenolate in Graves' orbitopathy. J Endocrinol Invest. 2020 Jun; 43(6):767-77.

64 Eid L, Coste-Verdier V, Longueville E, Ribeiro E, Nicolescu-Catargi B, Korobelnik JF. The effects of rituximab on Graves' orbitopathy: a retrospective study of 14 patients. Eur J Ophthalmol. doi: 10.1177/1120672119845224 [Epub ahead of print].

65 Chen B, Tsui S, Smith TJ. IL-1 beta induces IL-6 expression in human orbital fibroblasts: identification of an anatomic-site specific phenotypic attribute relevant to thyroid-associated ophthalmopathy. J Immunol. $2005 \mathrm{Jul}$; 175(2):1310-9.

66 Hwang CJ, Afifiyan N, Sand D, Naik V, Said J, Pollock SJ, et al. Orbital fibroblasts from patients with thyroid-associated ophthalmopathy overexpress CD40: CD154 hyperinduces IL-6, IL-8, and MCP-1. Invest Ophthalmol Vis Sci. 2009 May;50(5):2262-8.

67 Kumar S, Schiefer R, Coenen MJ, Bahn RS. A stimulatory thyrotropin receptor antibody (M22) and thyrotropin increase interleukin-6 expression and secretion in Graves' orbital preadipocyte fibroblasts. Thyroid. 2010 Jan; 20(1):59-65.

68 Khong JJ, McNab AA, Ebeling PR, Craig JE, Selva D. Pathogenesis of thyroid eye disease: review and update on molecular mechanisms. Br J Ophthalmol. 2016 Jan;100(1):142-50.
69 Jyonouchi SC, Valyasevi RW, Harteneck DA, Dutton CM, Bahn RS. Interleukin-6 stimulates thyrotropin receptor expression in human orbital preadipocyte fibroblasts from $\mathrm{pa}$ tients with Graves' ophthalmopathy. Thyroid. 2001 Oct;11(10):929-34.

70 Fang S, Huang Y, Zhong S, Li Y, Zhang Y, Li $Y$, et al. Regulation of Orbital Fibrosis and Adipogenesis by Pathogenic Th17 Cells in Graves Orbitopathy. J Clin Endocrinol Metab. 2017 Nov; 102(11):4273-83.

71 Fang S, Huang Y, Wang N, Zhang S, Zhong S, $\mathrm{Li} Y$, et al. Insights Into Local Orbital Immunity: Evidence for the Involvement of the Th17 Cell Pathway in Thyroid-Associated Ophthalmopathy. J Clin Endocrinol Metab. 2019 May;104(5):1697-711.

72 Jones BE, Maerz MD, Buckner JH. IL-6: a cytokine at the crossroads of autoimmunity. Curr Opin Immunol. 2018 Dec;55:9-14.

73 Molnár I, Balázs C. High circulating IL-6 level in Graves' ophthalmopathy. Autoimmunity. 1997;25(2):91-6.

74 Xu N, Cui Y, Fu D, Sun F. Tear inflammatory cytokines and ocular surface changes in patients with active thyroid eye disease treated with high-dose intravenous glucocorticoids. J Endocrinol Invest. 2020 Jul;43(7):901-10.

75 Pérez-Moreiras JV, Alvarez-López A, Gómez EC. Treatment of active corticosteroid-resistant Graves' orbitopathy. Ophthal Plast Reconstr Surg. 2014 Mar-Apr;30(2):162-7.

76 Sy A, Eliasieh K, Silkiss RZ. Clinical Response to Tocilizumab in Severe Thyroid Eye Disease. Ophthal Plast Reconstr Surg. 2017 May/ Jun;33(3):e55-7.

77 Russell DJ, Wagner LH, Seiff SR. Tocilizumab as a steroid sparing agent for the treatment of Graves' orbitopathy. Am J Ophthalmol Case Rep. 2017 Jul;7:146-8.

78 Canas CA, Bonilla-Abadia F, Vallejo K, Rengifo HM, Gallon MA, Tobon GJ. Successful Treatment for Severe Thyroid-associated Ophthalmopathy with Tocilizumab. Endocr Metab Immune Disord Drug Targets. 2018; 18(6):665-7.

79 Maldiney T, Deschasse C, Bielefeld P. Tocilizumab for the Management of Corticosteroid-Resistant Mild to Severe Graves' Ophthalmopathy, a Report of Three Cases. Ocul Immunol Inflamm. 2020;28(2):281-4.

80 Perez-Moreiras JV, Gomez-Reino JJ, Maneiro JR, Perez-Pampin E, Romo Lopez A, Rodríguez Alvarez FM, et al.; Tocilizumab in Graves Orbitopathy Study Group. Efficacy of Tocilizumab in Patients With Moderate-toSevere Corticosteroid-Resistant Graves Orbitopathy: A Randomized Clinical Trial. Am J Ophthalmol. 2018 Nov;195:181-90.

81 Bartalena L, Veronesi G, Krassas GE, Wiersinga WM, Marcocci C, Marinò M, et al.; European Group on Graves' Orbitopathy (EUGOGO). Does early response to intravenous glucocorticoids predict the final outcome in patients with moderate-to-severe and active Graves' orbitopathy? J Endocrinol Invest. 2017 May;40(5):547-53.
Novel Treatments for Graves'

Hyperthyroidism and Orbitopathy
Eur Thyroid J 2020;9(suppl 1):17-30 DOI: $10.1159 / 000508789$ 
82 Weightman DR, Perros P, Sherif IH, KendallTaylor P. Autoantibodies to IGF-1 binding sites in thyroid associated ophthalmopathy. Autoimmunity. 1993;16(4):251-7.

83 Pritchard J, Han R, Horst N, Cruikshank WW, Smith TJ. Immunoglobulin activation of $\mathrm{T}$ cell chemoattractant expression in fibroblasts from patients with Graves' disease is mediated through the insulin-like growth factor I receptor pathway. J Immunol. 2003 Jun; 170(12):6348-54.

84 Tsui S, Naik V, Hoa N, Hwang CJ, Afifiyan NF, Sinha Hikim A, et al. Evidence for an association between thyroid-stimulating hormone and insulin-like growth factor 1 receptors: a tale of two antigens implicated in Graves' disease. J Immunol. 2008 Sep;181(6): 4397-405.

85 Douglas RS, Gianoukakis AG, Kamat S, Smith TJ. Aberrant expression of the insulin-like growth factor-1 receptor by $\mathrm{T}$ cells from patients with Graves' disease may carry functional consequences for disease pathogenesis. J Immunol. 2007 Mar;178(5):3281-7.

86 Douglas RS, Naik V, Hwang CJ, Afifiyan NF, Gianoukakis AG, Sand D, et al. B cells from patients with Graves' disease aberrantly express the IGF-1 receptor: implications for disease pathogenesis. J Immunol. 2008 Oct; 181(8):5768-74.

87 Smith TJ, Janssen JA. Insulin-like Growth Factor-I Receptor and Thyroid-Associated Ophthalmopathy. Endocr Rev. 2019 Feb; 40(1):236-67.

88 Minich WB, Dehina N, Welsink T, Schwiebert C, Morgenthaler NG, Köhrle J, et al. Autoantibodies to the IGF1 receptor in Graves' orbitopathy. J Clin Endocrinol Metab. 2013 Feb; 98(2):752-60.
89 Marinò M, Rotondo Dottore G, Ionni I, Lanzolla G, Sabini E, Ricci D, et al. Serum antibodies against the insulin-like growth factor-1 receptor (IGF-1R) in Graves' disease and Graves' orbitopathy. J Endocrinol Invest. 2019 Apr;42(4):471-80.

90 Krieger CC, Place RF, Bevilacqua C, MarcusSamuels B, Abel BS, Skarulis MC, et al. TSH/ IGF-1 Receptor Cross Talk in Graves' Ophthalmopathy Pathogenesis. J Clin Endocrinol Metab. 2016 Jun;101(6):2340-7.

91 Marcus-Samuels B, Krieger CC, Boutin A, Kahaly GJ, Neumann S, Gershengorn MC. Evidence That Graves' Ophthalmopathy Immunoglobulins Do Not Directly Activate IGF-1 Receptors. Thyroid. 2018 May;28(5): 650-5.

92 Chen H, Mester T, Raychaudhuri N, Kauh CY, Gupta S, Smith TJ, et al. Teprotumumab, an IGF-1R blocking monoclonal antibody inhibits TSH and IGF-1 action in fibrocytes. J Clin Endocrinol Metab. 2014 Sep;99(9): E1635-40.

93 Chen H, Shan SJ, Mester T, Wei YH, Douglas RS. TSH-Mediated TNFa Production in Human Fibrocytes Is Inhibited by Teprotumumab, an IGF-1R Antagonist. PLoS One. 2015 Jun;10(6):e0130322.

94 Smith TJ, Kahaly GJ, Ezra DG, Fleming JC, Dailey RA, Tang RA, et al. Teprotumumab for Thyroid-Associated Ophthalmopathy. N Engl J Med. 2017 May;376(18):1748-61.
95 Douglas RS, Kahaly GJ, Patel A, Sile S, Thompson EH, Perdok R, et al. Teprotumumab for the Treatment of Active Thyroid Eye Disease. N Engl J Med. 2020 Jan;382(4): 341-52.

96 Douglas RS. Teprotumumab, an insulin-like growth factor-1 receptor antagonist antibody, in the treatment of active thyroid eye disease: a focus on proptosis. Eye (Lond). 2019 Feb;33(2):183-90.

97 Braun TL, Bhadkamkar MA, Jubbal KT, Weber AC, Marx DP. Orbital Decompression for Thyroid Eye Disease. Semin Plast Surg. 2017 Feb;31(1):40-5.

98 Smith TJ, Bartalena L. Will biological agents supplant systemic glucocorticoids as the first-line treatment for thyroid-associated ophthalmopathy? Eur J Endocrinol. 2019 Nov;181(5):D27-43.

99 Sipkova Z, Insull EA, David J, Turner HE, Keren S, Norris JH. Early use of steroidsparing agents in the inactivation of moderate-to-severe active thyroid eye disease: a step-down approach. Clin Endocrinol (Oxf). 2018 Dec;89(6):834-9.

100 Insull EA, Sipkova Z, David J, Turner HE, Norris JH. Early low-dose rituximab for active thyroid eye disease: an effective and well-tolerated treatment. Clin Endocrinol (Oxf). 2019 Jul;91(1):179-86.

101 Chang S, Perry JD, Kosmorsky GS, Braun WE. Rapamycin for treatment of refractory dysthyroid compressive optic neuropathy. Ophthal Plast Reconstr Surg. 2007 May-Jun; 23(3):225-6.

102 Roos JC, Murthy R. Sirolimus (rapamycin) for the targeted treatment of the fibrotic sequelae of Graves' orbitopathy. Eye (Lond). 2019 Apr;33(4):679-82. 